Article

\title{
Elucidation of the Mechanism Underlying the Anti-Inflammatory Properties of (S)-(+)-Carvone Identifies a Novel Class of Sirtuin-1 Activators in a Murine Macrophage Cell Line
}

\author{
Cátia Sousa ${ }^{1,2,3}$, Bruno Miguel Neves ${ }^{4}\left(\mathbb{D}\right.$, Alcino Jorge Leitão ${ }^{1,2,3}\left(\mathbb{D}\right.$ and Alexandrina Ferreira Mendes ${ }^{1,2,3, *(\mathbb{D})}$ \\ 1 Centre for Neuroscience and Cell Biology, University of Coimbra, 3004-504 Coimbra, Portugal; \\ uc45185@uc.pt (C.S.); ajleitao@ff.uc.pt (A.J.L.) \\ 2 Faculty of Pharmacy, University of Coimbra, 3000-548 Coimbra, Portugal \\ 3 Centre for Innovative Biomedicine and Biotechnology, University of Coimbra, 3004-504 Coimbra, Portugal \\ 4 Department of Medical Sciences and Institute of Biomedicine-iBiMED, University of Aveiro, \\ 3810-193 Aveiro, Portugal; bruno.neves@ua.pt \\ * Correspondence: afmendes@ff.uc.pt
}

\section{check for}

updates

Citation: Sousa, C.; Neves, B.M.; Leitão, A.J.; Mendes, A.F. Elucidation of the Mechanism Underlying the Anti-Inflammatory Properties of (S)-(+)-Carvone Identifies a Novel Class of Sirtuin-1 Activators in a Murine Macrophage Cell Line. Biomedicines 2021, 9, 777. https:// doi.org/10.3390/biomedicines9070777

Academic Editor:

Konstantinos Dimas

Received: 7 May 2021

Accepted: 1 July 2021

Published: 4 July 2021

Publisher's Note: MDPI stays neutral with regard to jurisdictional claims in published maps and institutional affiliations.

Copyright: (c) 2021 by the authors. Licensee MDPI, Basel, Switzerland. This article is an open access article distributed under the terms and conditions of the Creative Commons Attribution (CC BY) license (https:// creativecommons.org/licenses/by/ $4.0 /$ )

\begin{abstract}
The signaling pathways involved in age-related inflammation are increasingly recognized as targets for the development of preventive and therapeutic strategies. Our previous study elucidated the structure-activity relationship of monoterpene compounds derived from $p$-menthane as potential anti-inflammatory drugs and identified (S)-(+)-carvone as the most potent among the compounds tested. This study aims at identifying the molecular mechanism underlying the antiinflammatory properties of (S)-(+)-carvone. The murine macrophage cell line, Raw 264.7, was stimulated with bacterial lipopolysaccharide (LPS) to simulate inflammation. Western blot was used to assess protein levels and post-translational modifications. The subcellular localization of $\mathrm{NF}-\mathrm{kB} / \mathrm{p} 65$ was visualized by immunocytochemistry. An in vitro fluorometric assay was used to measure Sirtuin-1 (SIRT1) activity. (S)-(+)-carvone inhibited LPS-induced JNK1 phosphorylation, but not that of p38 and ERK1/2 and also did not affect the phosphorylation and degradation of the NF- $\kappa B$ inhibitor, I $\mathrm{kB}-\alpha$. Accordingly, (S)-(+)-carvone did not affect LPS-induced phosphorylation of NF- $\kappa \mathrm{B} / \mathrm{p} 65$ on Ser536 and its nuclear translocation, but it significantly decreased LPS-induced IкB- $\alpha$ resynthesis, a NF-kB-dependent process, and NF-kB/p65 acetylation on lysine (Lys) 310. Deacetylation of that Lys residue is dependent on the activity of SIRT1, which was found to be increased by (S)-(+)-carvone, while its protein levels were unaffected. Taken together, these results show that (S)-(+)-carvone is a new SIRT1 activator with the potential to counteract the chronic low-grade inflammation characteristic of age-related diseases.
\end{abstract}

Keywords: aging; inflammation; monoterpene; NF-кB; Sirtuin-1; Sirtuin-1 activating compound

\section{Introduction}

Persistent low-grade inflammation represents a pathological mechanism associated with age-related diseases, such as metabolic, cardiovascular, neurodegenerative and musculoskeletal diseases and cancer [1]. A large range of stimuli, including inflammatory cytokines (e.g., Interleukin (IL)-1 $\beta$, Tumor Necrosis Factor- $\alpha$ (TNF- $\alpha$ ) and IL6), microbial products, cellular components released by dead or damaged cells (e.g., ATP and the alarmins, HMGB1 and members of the S100 family) [2] and intermittent hypoxia, especially in older people [3], activate multiple intracellular signaling cascades that bring about the inflammatory response. Of those signaling cascades, members of the Mitogen-Activated Protein Kinase (MAPK) family and the transcription factor, Nuclear Factor kappa-lightchain-enhancer of activated B cells (NF- $k B$ ), are especially relevant. Numerous studies have shown that their activation leads to the production of inflammatory mediators and 
effector enzymes that drive and perpetuate inflammation-associated tissue damage and functional impairment, thus promoting disease development and/or progression [2,4].

Considering the role of MAPKs and NF-KB in chronic inflammation and the lack of efficient therapeutic strategies for chronic inflammation-associated diseases, the signaling pathways that lead to their activation are promising targets for drug development $[5,6]$.

Our previous work screened various compounds of natural origin in standardized conditions, to identify small molecules capable of interfering with those inflammatory pathways and to establish the structural features required for activity. (S)-(+)-carvone (Figure 1), a limonene-derived monoterpene especially abundant in mint species, was identified as the lead compound of that series, decreasing inducible Nitric Oxide (NO) Synthase (NOS2) and IL-1 $\beta$ expression, both in a mouse macrophage cell line and in primary human chondrocytes, in response to LPS and IL-1 $\beta$, respectively [7]. These results are in line with other studies reporting anti-inflammatory [8], antioxidant [9], antihiperglycemic and hyperlipidemic $[10,11]$ properties of $(S)-(+)$-carvone or the racemic mixture that also contains its (R)-(-) enantiomer. Nonetheless, the molecular mechanism(s) underlying those effects of (S)-(+)-carvone are not fully understood.<smiles>C=C(C)[C@H]1CC=C(C)C(=O)C1</smiles>

Figure 1. Structural formula of (S)-(+)-carvone.

Therefore, the purpose of this work was to elucidate the molecular mechanism(s) by which (S)-(+)-carvone interferes with the expression of pro-inflammatory mediators. Considering the crucial role of MAPKs and NF- $\mathrm{KB}$ activation on pro-inflammatory gene expression, we hypothesized that these signaling pathways may be targeted by (S)-(+)carvone. The results obtained confirm this hypothesis and allow for further insight into the molecular mechanism of action of (S)-(+)-carvone, showing that it directly activates Sirtuin-1 (SIRT1), a NAD+-dependent deacetylase known to target the p65 component of NF- $\mathrm{kB}$, decreasing its transcriptional activity [12].

\section{Materials and Methods}

\subsection{Cell Culture and Treatments}

The mouse macrophage cell line, Raw 264.7 (ATCC No. TIB-71, Manassas, VA, USA), was cultured in DMEM (ThermoFisher Scientific, Walthman, MA, USA) supplemented with 10\% non-inactivated fetal bovine serum (FBS; ThermoFisher Scientific), $100 \mathrm{U} / \mathrm{mL}$ penicillin (Sigma-Aldrich Co., St Louis, MO, USA) and $100 \mu \mathrm{g} / \mathrm{mL}$ streptomycin (SigmaAldrich Co.). Raw 264.7 cells were plated at a density of $3 \times 10^{5}$ cells $/ \mathrm{mL}$ and left to stabilize for up to $24 \mathrm{~h}$. The cells were used between passages 25 and 40 , as we verified that the usual responses to LPS are maintained in this range.

For cell treatments, (S)-(+)-carvone (\#435759, purity 96\%, Sigma-Aldrich Co.), resveratrol (Res; Extrasynthese, Genay Cedex, France), Bay 11-7082 (Calbiochem, San Diego, CA, USA) and MG-132 (Z-Leu-Leu-Leu-CHO, Boston Biochem, Cambridge, MA, USA) were dissolved in dimethyl sulfoxide (DMSO; Sigma-Aldrich Co.). LPS from Escherichia coli 026:B6 (Sigma-Aldrich Co.) was dissolved in phosphate-buffered saline (PBS). The concentrations of each compound and the experimental treatment periods are indicated in figures and/or figure legends. Concentrations of (S)-(+)-carvone were selected based on our previous work [6]. DMSO was used as vehicle and added to control and LPS-treated cell cultures to match the same concentration as in cells treated with the chemicals indicated above. In any case, the final concentration of DMSO was $0.1 \%(v / v)$. The chemicals used or 
the vehicle were added to murine macrophage cultures $1 \mathrm{~h}$ before the pro-inflammatory stimulus, $1 \mu \mathrm{g} / \mathrm{mL}$ LPS, and maintained for the rest of the experimental period.

\subsection{Preparation of Cell Extracts}

For the preparation of total cell extracts, cell cultures were washed with ice-cold PBS and lysed with ice-cold RIPA buffer [ $150 \mathrm{mM}$ sodium chloride (ThermoFisher Scientific), $50 \mathrm{mM}$ Tris (ThermoFisher Scientific, pH 7.5), $5 \mathrm{mM}$ ethylene glycol-bis(2-aminoethylether)$\mathrm{N}, \mathrm{N}, \mathrm{N}^{\prime}, \mathrm{N}^{\prime}$-tetraacetic acid (EGTA; Sigma-Aldrich Co.), $0.5 \%$ sodium deoxycholate (SigmaAldrich Co.), 0.1\% sodium dodecyl sulfate (SDS; Sigma-Aldrich Co.), 1\% Triton X-100 (Merck Millipore Ltd., Darmstadt, Germany) ] supplemented with protease (Complete, Mini, Roche Diagnostics, Mannheim, Germany) and phosphatase (PhosSTOP, Roche Diagnostics, Mannheim, Germany) inhibitor cocktails, for $30 \mathrm{~min}$. The lysates were centrifuged at $14,000 \mathrm{rpm}$ for $10 \mathrm{~min}$ at $4{ }^{\circ} \mathrm{C}$ and the supernatants were stored at $-20^{\circ} \mathrm{C}$ until use.

For the preparation of cytoplasmic and nuclear extracts, the Nuclear Extract Kit (Active Motif, La Hulpe, Belgium) was used, following the manufacturer's instructions.

Protein concentration in the extracts was determined with the bicinchoninic acid kit (Sigma-Aldrich Co.).

\subsection{Western Blotting}

Western blot was performed as described previously [13]. Briefly, total (25 $\mu \mathrm{g})$, cytoplasmic $(25 \mu \mathrm{g})$ or nuclear $(30 \mu \mathrm{g})$ proteins were separated by SDS-PAGE under reducing conditions. A commercial mixture of 12 purified pre-stained proteins (NZYColour Protein Marker II, NZYTech, Lisbon, Portugal) was run in each gel to allow for confirmation of the apparent molecular weight of the proteins of interest. The proteins were then electrotransferred onto PVDF membranes (Immobilon ${ }^{\circledR}-\mathrm{P}$, Merck Millipore Ltd.) which were probed overnight at $4{ }^{\circ} \mathrm{C}$ or for $2 \mathrm{~h}$ at room temperature with the primary antibodies indicated in Table 1 and then with anti-rabbit (dilution 1:20,000; NIF1317, lot9465473, GE Healthcare, Chalfont St. Giles, UK) or anti-mouse (dilution 1:20,000; NIF1316, lot6963606, GE Healthcare, Chalfont St. Giles, UK) alkaline phosphatase-conjugated secondary antibodies. Mouse monoclonal anti- $\beta$-Tubulin I and rabbit polyclonal anti-Lamin B1 were used as a loading controls of total and cytoplasmic extracts and of nuclear extracts, respectively. Immune complexes were detected with Enhanced ChemiFluorescence reagent (GE Healthcare) in the imaging system Thyphoon ${ }^{\mathrm{TM}}$ FLA 9000 (GE Healthcare). Image analysis was performed with TotalLab TL120 software (Nonlinear Dynamics Ltd., Newcastle upon Tyne, UK).

Table 1. List of primary antibodies used in Western blot assays.

\begin{tabular}{|c|c|c|c|c|c|}
\hline Protein & Source & Clonality & Dilution & Supplier & Catalogue/Lot Number \\
\hline IкB- $\alpha$ & rabbit & polyclonal & 1:1000 & $\begin{array}{l}\text { Cell Signaling Technology, Inc., } \\
\text { Danvers, MA, USA }\end{array}$ & $\# 9242 / 9$ \\
\hline $\begin{array}{l}\text { phospho-p44/42 MAPK (ERK1/2) } \\
\text { (Thr202/Tyr204) }\end{array}$ & rabbit & polyclonal & $1: 1000$ & Cell Signaling Technology, Inc. & \#9101/27 \\
\hline p44/42 MAPK (ERK1/2) & rabbit & polyclonal & $1: 1000$ & Cell Signaling Technology, Inc. & \#9102/26 \\
\hline $\begin{array}{l}\text { phospho-p38 MAPK } \\
\text { (Thr180/Tyr182) }\end{array}$ & rabbit & polyclonal & $1: 1000$ & Cell Signaling Technology, Inc. & \#9211/21 \\
\hline p38 MAPK & rabbit & polyclonal & $1: 1000$ & Cell Signaling Technology, Inc. & $\# 9212 / 17$ \\
\hline SAPK/JNK & rabbit & polyclonal & $1: 1000$ & Cell Signaling Technology, Inc. & $\# 9252 / 17$ \\
\hline $\begin{array}{l}\text { acetyl-NF-kB p65 } \\
\text { (Lys310) }\end{array}$ & rabbit & polyclonal & $1: 750$ & Cell Signaling Technology, Inc. & $\# 3045 / 2$ \\
\hline Sirtuin-1 & rabbit & polyclonal & 1:1000 & Sigma-Aldrich Co. & $07-131 / 2736563$ \\
\hline Lamin B1 & rabbit & polyclonal & $1: 1000$ & Abcam, Cambridge, UK & ab16048/GR48958-1 \\
\hline
\end{tabular}


Table 1. Cont.

\begin{tabular}{|c|c|c|c|c|c|}
\hline Protein & Source & Clonality & Dilution & Supplier & Catalogue/Lot Number \\
\hline $\begin{array}{c}\text { phospho-SAPK/JNK } \\
\text { (Thr183/Tyr185) }\end{array}$ & rabbit & monoclonal & $1: 1000$ & Cell Signaling Technology, Inc. & \#4668/11 \\
\hline NF-кB p65 (D14E12) XP ${ }^{\circledR}$ & rabbit & monoclonal & $1: 1000$ & Cell Signaling Technology, Inc. & $\# 8242 / 4$ \\
\hline $\begin{array}{c}\text { phospho- } \\
\text { NF-кB p65 (Ser536) }\end{array}$ & rabbit & monoclonal & $1: 1000$ & Cell Signaling Technology, Inc. & \#3033/14 \\
\hline phospho-IкB- $\alpha$ (Ser32/36) & mouse & monoclonal & $1: 1000$ & Cell Signaling Technology, Inc. & \#9246/14 \\
\hline$\beta$-Tubulin I & mouse & monoclonal & $1: 20,000$ & Sigma-Aldrich Co. & T7816/052M4835 \\
\hline
\end{tabular}

\subsection{Immunocytochemistry}

Macrophages were seeded onto $\mu$-Slide 8 Well chamber plates (ibiTreat, Ibidi, Martinsried, Germany) suitable for cell culture and microscopy, followed by immunostaining. After treatment, the cells were washed with ice-cold PBS pH $=7.4$ and then fixed in $4 \%$ paraformaldehyde (Sigma-Aldrich Co.) at room temperature, for $15 \mathrm{~min}$. After fixing, cells were washed three times with PBS $\mathrm{pH}=7.4$ with $0.1 \mathrm{M}$ glycine (ThermoFisher Scientific) for 5 min each and blocked with 5\% Goat Serum (Sigma-Aldrich Co.), 0.3\% Triton X-100 in PBS, $\mathrm{pH}=7.4$ for $1 \mathrm{~h}$ at room temperature. Then, the slides were incubated with a rabbit monoclonal anti-NF-kB p65 (D14E12) XP ${ }^{\circledR}$ antibody (dilution 1:400; \#8242, Lot 4, Cell Signaling Technology, Inc., Danvers, MA, USA) in 1\% Bovine Serum Albumin (Merck Millipore Ltd.) in PBS ( $\mathrm{pH}=7.4)$, overnight at $4{ }^{\circ} \mathrm{C}$. The cells were washed three times with PBS $(\mathrm{pH}=7.4)$ for $5 \mathrm{~min}$ each at room temperature and incubated for $1 \mathrm{~h}$ at room temperature with anti-rabbit $\operatorname{IgG}(\mathrm{H}+\mathrm{L}) \mathrm{CF}^{\mathrm{TM}} 488 \mathrm{~A}$ antibody (dilution 1:400; SAB4600165, Lot $10 \mathrm{C} 0615$ Biothium, Inc., Fremont, CA, USA). Following three washes with PBS $(\mathrm{pH}=7.4)$, the cells were counterstained with DAPI $(0.2 \mathrm{ng} / \mathrm{mL}$; Molecular Probes, Invitrogen, Eugene, OR, USA) to allow for nucleus visualization, and after another washing step, the slides were mounted with Ibidi Mounting Medium (Ibidi, Martinsried, Germany). Specificity was evaluated in negative controls set up by omitting the primary antibody. Fluorescence images were obtained in an Axio Observer ZI fluorescence microscope (Carl Zeiss, Germany).

\subsection{SIRT1 Activity Assay}

Interaction of (S)-(+)-carvone with human SIRT1 was evaluated using the SIRT1 Direct Fluorescent Screening Assay Kit (Cayman Chemical Company, Ann Arbor, MI, USA) following the manufacturer's instructions. Briefly, the assay uses a specific substrate, in this case, a peptide derived from the p53 sequence, coupled to a fluorophore (Arg-HisLys-Lys(e-acetyl)-AMC), which is incubated with recombinant human SIRT1 along with its co-substrate, $\mathrm{NAD}^{+}$. Deacetylation sensitizes the substrate such that treatment with a developer reagent releases a fluorescent product. The activity of the enzyme is proportional to the fluorescence intensity. The ability of resveratrol to activate the enzyme was evaluated in parallel assays as a positive control. The results are presented as mean fluorescence intensity (arbitrary units) \pm SEM.

\subsection{Statistical Analysis}

The results are presented as mean \pm SEM. Statistical analysis was performed using GraphPad Prism version 6.0 (GraphPad Software, San Diego, CA, USA). Statistical significance was evaluated with the $t$-test to compare each condition with its respective control or with one-way ANOVA with the Dunnett post-test for comparison of multiple conditions to a control group. A non-parametric test (Mann-Whitney test to compare each condition to the basal SIRT1 activity) was used to assess the statistical significance of the differences observed in Figure $7 \mathrm{c}$, as those results did not follow a normal distribution. The results were considered statistically significant at $p<0.05$. 


\section{Results}

\section{1. (S)-(+)-Carvone Decreases JNK1 Phosphorylation Induced by LPS in Macrophages}

The effects of (S)-(+)-carvone on activation of the three MAPK subfamilies, namely, Extracellular-signal Regulated Kinase (ERK) 1/2, p38 and Jun N-terminal Kinase (JNK), were evaluated by measuring their phosphorylated levels in response to macrophage stimulation with LPS.

The results obtained show that LPS induced the phosphorylation of p38 (Figure 2a) and JNK (Figure $2 \mathrm{~b}$ ) very rapidly, being detectable as early as five minutes after the addition of LPS. Pre-treatment with (S)-(+)-carvone had no effect on p38 phosphorylation (Figure 2a), while significantly decreasing JNK1 phosphorylation to, approximately, 38\% of the levels found in cells treated with LPS alone (Figure 2b). Furthermore, a tendency for reduced JNK2 and 3 phosphorylation was also observed, but in no case did it reach statistical significance (Figure 2b).

a

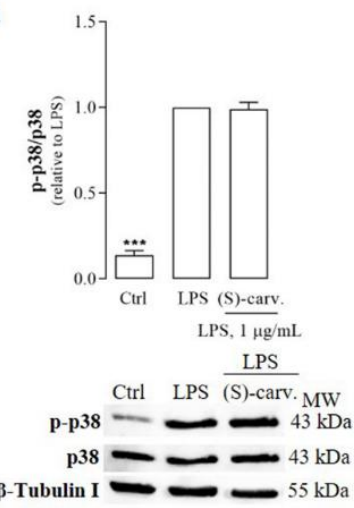

b
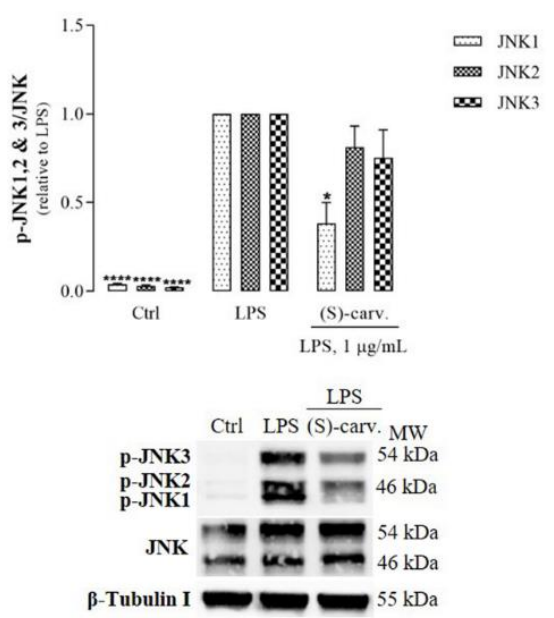

c

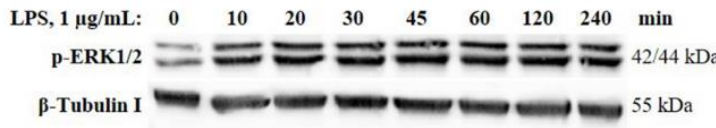

d

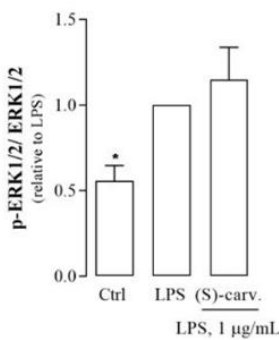

LPS

Ctrl LPS (S)-carv.

p-ERK1 $12=02 / 44 \mathrm{kDa}$

ERK $1 / 2 \cong=02 / 44 \mathrm{kD}$

ß-Tubulin I $=55 \mathrm{kDa}$

Figure 2. Effect of (S)-(+)-carvone on p38 (a), JNK (b) and ERK1/2 (d) activation. Raw 264.7 macrophage cultures were pre-treated with $665 \mu \mathrm{M}(\mathrm{S})-(+)$-carvone [(S)-carv.] for $1 \mathrm{~h}$ before addition of $1 \mu \mathrm{g} / \mathrm{mL}$ LPS for $5 \mathrm{~min}(\mathbf{a})$ and (b), the time periods indicated in (c) or $1 \mathrm{~h}(\mathbf{d})$. Control cells (Ctrl) were treated with the vehicle alone $(0.1 \%$ DMSO) for the same time periods, except in c, where control cells were untreated. Each column represents the mean \pm SEM of four (a) and (b) or three (d) independent experiments. Representative images are shown. ${ }^{*} p<0.05,{ }^{* * *} p<0.001$ and ${ }^{* * * *} p<0.0001$ relative to LPS-treated cells. MW: molecular weight marker. 
ERK1/2 phosphorylation, however, was undetectable at the same time point (5 min). Thus, we performed a time course experiment to determine the best condition. As shown in Figure 2c, maximal phosphorylation occurred between 45 and 60 min after the addition of LPS to the cell cultures and was sustained for up to $120 \mathrm{~min}$, starting to slowly decrease thereafter. Thus, to ensure that maximal ERK1/2 phosphorylation was achieved in all experiments, we chose the $60 \mathrm{~min}$ treatment period for subsequent experiments. The results obtained (Figure $2 \mathrm{~d}$ ) show that $(\mathrm{S})-(+)$-carvone was unable to decrease LPS-induced ERK1/2 phosphorylation.

\section{2. (S)-(+)-Carvone Does Not Interfere with the Canonical NF- $\kappa B$ Activation Pathway}

NF-кB-inducing signals, like LPS upon binding to TLR4, trigger the activation of the I $\kappa$ B kinase complex (IKK) which phosphorylates I $\kappa B-\alpha$, the natural inhibitor of NF- $\kappa B$. Once phosphorylated, I $\mathrm{B} B-\alpha$ is ubiquitinated and, subsequently, undergoes proteasomal degradation, releasing the NF- $\mathrm{BB}$ dimers, composed of $\mathrm{p} 65$ and p50 proteins, which constitutes the canonical NF- $\kappa$ B activation pathway. Upon release from I $\kappa$ B $-\alpha$, the NF- $k B$ dimers translocate to the nucleus and undergo several modifications that modulate their transcriptional activity on target genes [14].

Since the phosphorylation and degradation of $\mathrm{I} \kappa \mathrm{B}-\alpha$ are essential for NF- $\kappa \mathrm{B}$ activation, the ability of (S)-(+)-carvone to interfere with these steps was evaluated. Figure 3a,b show that LPS $(1 \mu \mathrm{g} / \mathrm{mL})$ induced IкB- $\alpha$ phosphorylation and degradation, but $(\mathrm{S})-(+)$-carvone was unable to block or even decrease those LPS-induced responses at a concentration previously observed to be sufficient to significantly decrease inflammatory gene expression [7]. On the contrary, Bay 11-7082 (5 $\mu \mathrm{M})$, a selective NF- $\mathrm{BB}$ inhibitor, decreased LPS-induced I $\kappa$ B- $\alpha$ phosphorylation and degradation (Figure $3 a, b$ ), although the difference relative to cells treated with LPS alone did not reach statistical significance. Moreover, MG-132 $(10 \mu \mathrm{M})$, a synthetic proteasome inhibitor peptide, increased the levels of phosphorylated I $\mathrm{B}-\alpha$ induced by LPS (Figure 3a), showing that its proteasomal degradation was inhibited relative to LPS-treated cells (Figure $3 b$ ). These results confirm that LPS effectively activated the canonical NF- $\kappa$ B activation pathway, inducing I $\kappa$ B- $\alpha$ phosphorylation and degradation, which were not affected by (S)-(+)-carvone (Figure $3 a, b)$.

Another target of IKK is NF- $\mathrm{KB} / \mathrm{p} 65$, which is phosphorylated by this kinase on the Ser536 residue located in its transactivation domain $[15,16]$. Therefore, and to further confirm the results obtained for IкB- $\alpha$, the ability of (S)-(+)-carvone to interfere with LPSinduced NF-kB/p65 phosphorylation at Ser536 was explored. The results in Figure 3c show that the test compound was unable to decrease LPS-induced NF- $\mathrm{B} / \mathrm{p} 65$ phosphorylation on Ser536, further supporting that it does not interfere with the canonical NF- $\mathrm{B}$ activation pathway.

\subsection{NF- $\kappa B / p 65$ Nuclear Translocation Is Not Affected by (S)-(+)-Carvone}

Since (S)-(+)-carvone was unable to prevent IкB- $\alpha$ phosphorylation and degradation, we hypothesized that this compound could be interfering with NF- $\mathrm{kB}$ nuclear translocation. To explore this possibility, immunocytochemistry was performed to detect NF- $\mathrm{kB} / \mathrm{p} 65$ translocation to the nucleus. Figure 4 a shows that in vehicle-treated cells (Ctrl), NF- $\mathrm{B} / \mathrm{p} 65 \mathrm{im}-$ munoreactivity is clearly visible in the cytoplasm, while upon treatment with LPS $(1 \mu \mathrm{g} / \mathrm{mL})$, immunoreactivity is mainly located in the nucleus. Pre-treatment with $10 \mu \mathrm{M}$ of the proteasome inhibitor, MG-132, fully inhibited NF- $\mathrm{kB} / \mathrm{p} 65$ nuclear translocation, as immunoreactivity is mainly visible in the cytoplasm. Contrastingly, (S)-(+)-carvone was unable to prevent LPSinduced NF- $\mathrm{kB} /$ p65 nuclear translocation, as immunoreactivity is localized in the nucleus with no differences relative to cells treated with LPS alone (Figure 4a). 
$\mathbf{a}$

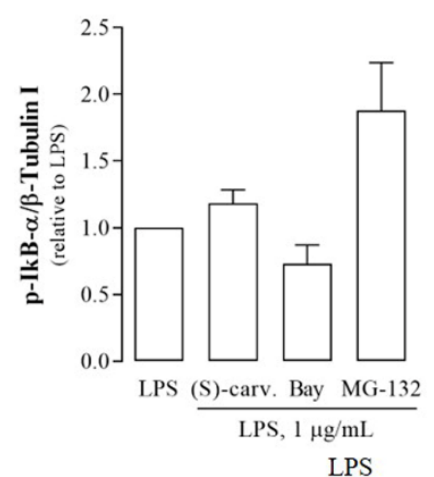

Ctrl LPS (S)-carv. Bay MG-132 MW

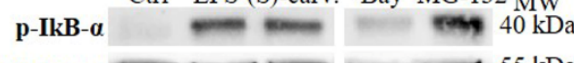

b

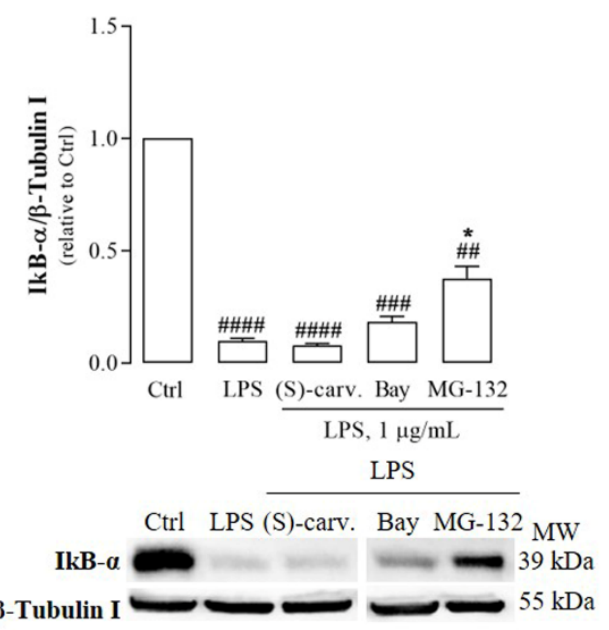

c
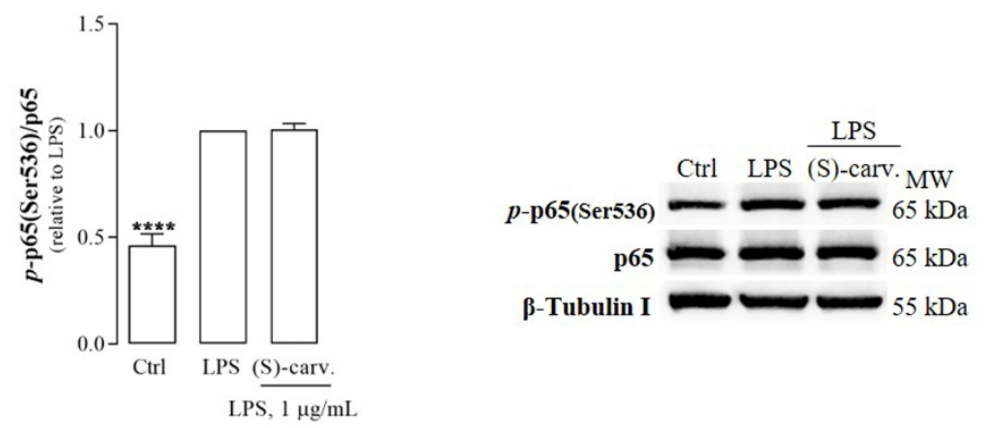

Figure 3. (S)-(+)-carvone does not interfere with the canonical NF- $\kappa B$ activation pathway, namely, phosphorylation (a) and

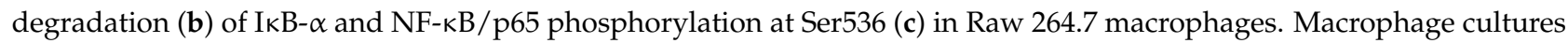
were treated with $1 \mu \mathrm{g} / \mathrm{mL}$ LPS for $5 \mathrm{~min}(\mathbf{a})$ or $15 \mathrm{~min}(\mathbf{b})$ and (c), following pre-treatment with the vehicle $(0.1 \%$ DMSO, Ctrl), $665 \mu \mathrm{M}$ (S)-(+)-carvone [(S)-carv.], $5 \mu \mathrm{M}$ of the selective IKK inhibitor, Bay 11-7082, or $10 \mu \mathrm{M}$ of the proteasome inhibitor, MG-132, for $1 \mathrm{~h}$. Each column represents the mean \pm SEM of five (a) or four (b) and (c) independent experiments. Representative images are shown. ${ }^{*} p<0.05$ and ${ }^{* * * *} p<0.0001$ relative to LPS-treated cells. ${ }^{\# \#} p<0.01,{ }^{\# \#} p<0.001$ and \#\#\#\# $p<0.0001$ relative to the Ctrl. MW: molecular weight marker.

Confirming these results, Western blot analysis shows that treatment with LPS decreased the cytoplasmic levels of NF-kB/p65 (Figure 4b, left side), while its nuclear levels were concomitantly increased (Figure $4 \mathrm{~b}$, right side), but they were not affected by treatment with (S)-(+)-carvone. Thus, these results corroborate those found in the immunofluorescence assay, collectively showing that (S)-(+)-carvone does not interfere with LPS-induced $\mathrm{NF}-\mathrm{kB} / \mathrm{p} 65$ release from complexes with IкB- $\alpha$ and nuclear translocation.

\subsection{NF- $\kappa B$ Transcriptional Activity Is Inhibited by $(S)-(+)$-Carvone}

Although (S)-(+)-carvone did not inhibit the canonical NF-kB activation pathway, our previous work demonstrated that this compound is capable of decreasing the expression of two NF- $\mathrm{kB}$ target genes and major inflammatory mediators, NOS2 and IL-1 $\beta$ [7]. Thus, and to further elucidate these findings, the protein product of another NF- $\mathrm{kB}$ target gene, the IкB- $\alpha$ gene [17], was also evaluated. For this, we performed a time course of stimulation with LPS to determine the time points where IкB- $\alpha$ degradation ended and its resynthesis started. IкB- $\alpha$ degradation was complete within 10 to $15 \mathrm{~min}$ after addition of LPS, whereas its resynthesis started at $20 \mathrm{~min}$ and reached its maximal level within $60 \mathrm{~min}$ (Figure 5a). Thus, using this time point, we determined that (S)-(+)-carvone is effective in preventing LPS-induced IкB- $\alpha$ resynthesis (Figure $5 b$ ), supporting the hypothesis that the anti-inflammatory effects of this compound involve the modulation of NF- $\mathrm{KB}$ activity. 


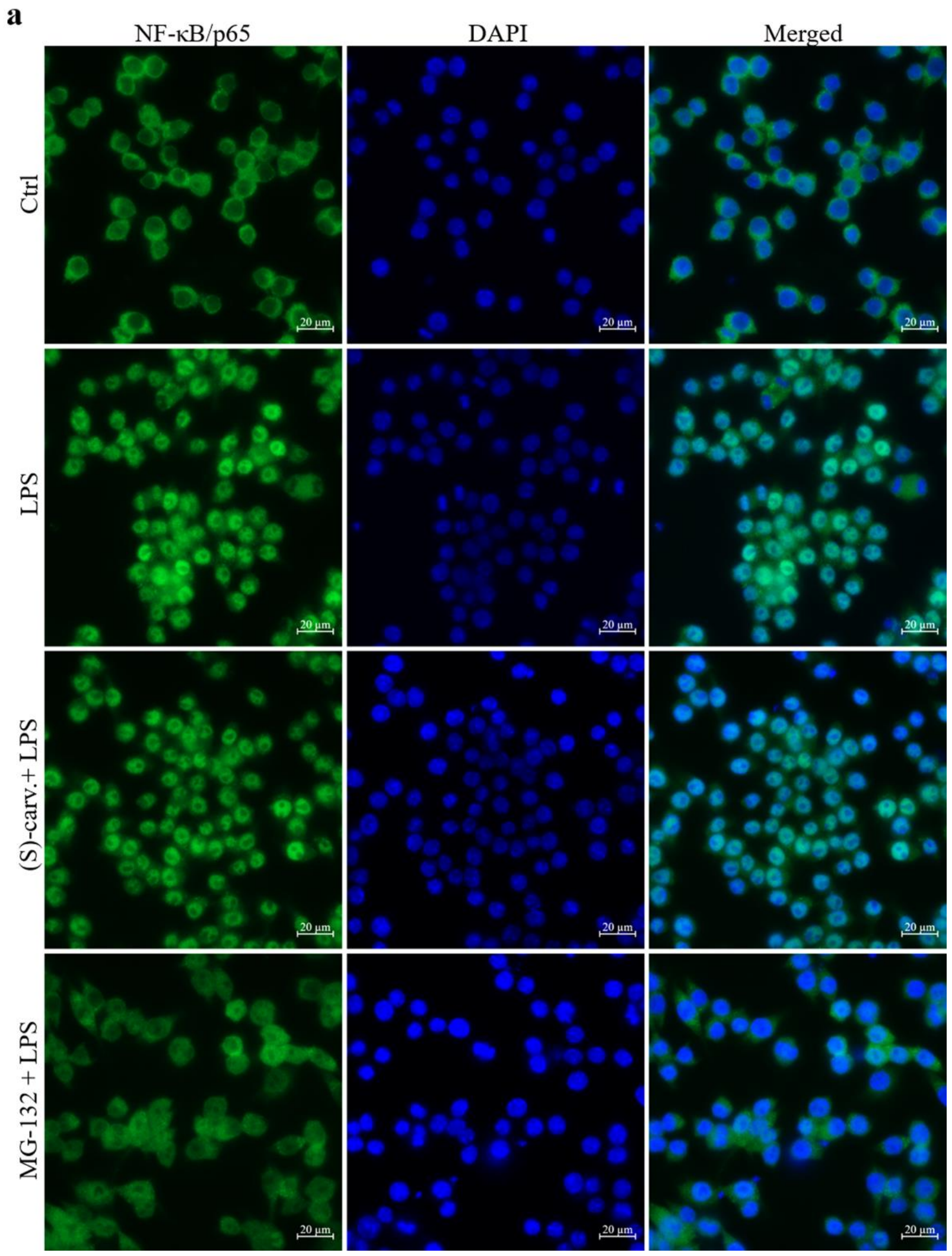

Figure 4. Cont. 
b

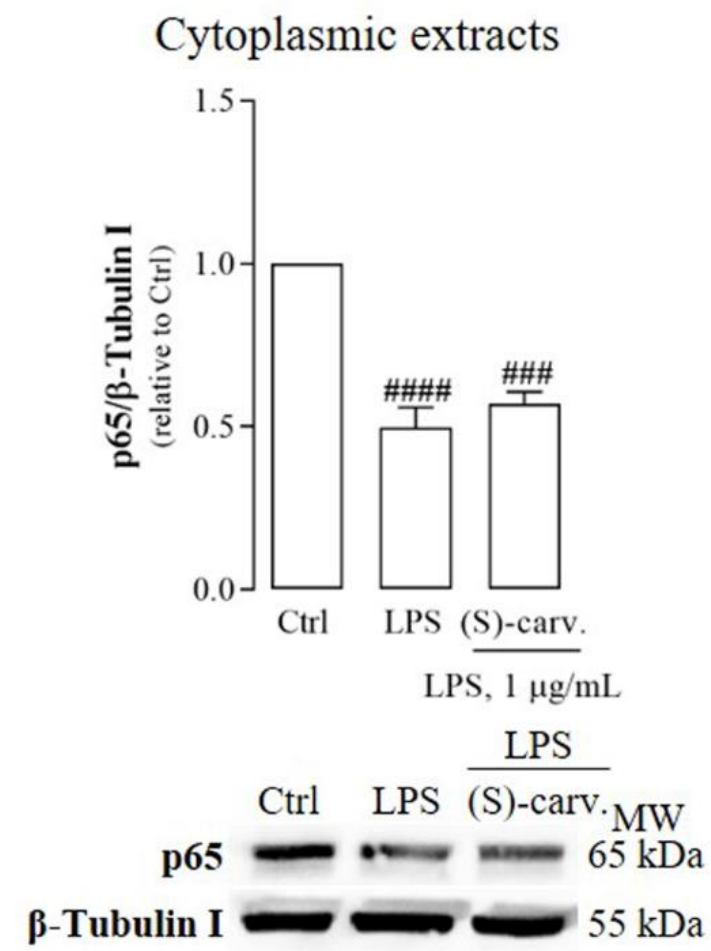

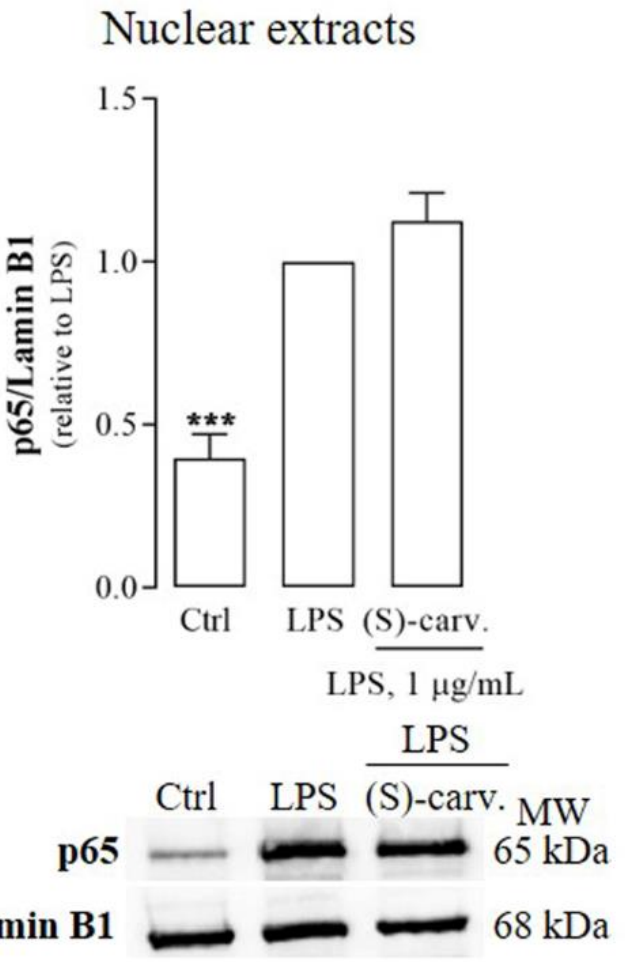

Figure 4. (S)-(+)-carvone does not inhibit NF- $\mathrm{BB}$ nuclear translocation. (a) Raw 264.7 macrophages were treated with $1 \mu \mathrm{g} / \mathrm{mL} \mathrm{LPS}$ for $20 \mathrm{~min}$, following pre-treatment with the vehicle (0.1\% DMSO), $665 \mu \mathrm{M}$ (S)-(+)-carvone [(S)-carv.] or $10 \mu \mathrm{M} \mathrm{MG-132,} \mathrm{for} 1 \mathrm{~h}$. Control cells (Ctrl) were treated with the vehicle alone. Immunofluorescence staining of NF- $\mathrm{kB} / \mathrm{p} 65$ (green) and fluorescence staining of the nuclei (blue) were performed as described in Materials and Methods. Scale bar $20 \mu \mathrm{m}$. Representative images of each condition are shown. (b) Macrophages were treated with $1 \mu \mathrm{g} / \mathrm{mL}$ LPS for $1 \mathrm{~h}$, following pre-treatment with the vehicle $(0.1 \%$ DMSO) or $665 \mu \mathrm{M}$ (S)-(+)-carvone [(S)-carv.] for $1 \mathrm{~h}$. Cytoplasmic (left side) and nuclear (right side) levels of RelA/p65 were evaluated by Western blot. Control cells (Ctrl) were treated with the vehicle alone. Each column represents the mean \pm SEM of three (cytoplasmic levels) and six (nuclear levels) independent experiments. Representative images are shown. ${ }^{* * *} p<0.001$ relative to LPS-treated cells. ${ }^{\# \#} p<0.001$ and \#\#\# $p<0.0001$ relative to the Ctrl. MW: molecular weight marker.

\section{5. (S)-(+)-Carvone Promotes NF- $\kappa B / p 65$ Deacetylation at Lys310}

Besides release from I $\kappa B-\alpha$ and nuclear translocation, NF- $\kappa B$ full transcriptional activity requires several modifications of NF- $\mathrm{kB} / \mathrm{p} 65$ which impact on DNA binding affinity, interaction with coactivators and corepressors and termination of the NF- $\mathrm{KB}$ response [18]. Thus, we hypothesized that (S)-(+)-carvone may interfere with one or more of those modifications. Among those, NF- $\mathrm{kB} / \mathrm{p} 65$ acetylation, particularly at Lys310, has been reported as essential for full NF- $\mathrm{kB}$ transcriptional activity [18]. Thus, we evaluated the levels of NF- $\mathrm{kB} / \mathrm{p} 65$ acetylated on Lys 310 induced by LPS, in the presence and absence of (S)-(+)-carvone or resveratrol (Res), a natural polyphenolic compound known to promote NF- $\mathrm{kB} / \mathrm{p} 65$ deacetylation [12] and used here as a positive pharmacological control. Figure 6 shows that treatment with LPS induced NF-kB/p65 acetylation on Lys310. Pretreatment with Res slightly decreased the levels of acetylated Lys 310 on NF- $\mathrm{kB} / \mathrm{p} 65$ without reaching statistical significance, likely because Res also inhibits the canonical NF- $\mathrm{kB}$ activation pathway, decreasing the nuclear levels of total NF-kB/p65 $[19,20]$, which causes the size of the effect of Res to be very small and prone to large variability. On the contrary, (S)-(+)-carvone significantly decreased those levels, suggesting that this effect can be the mechanism by which the compound inhibits NF-kB activity. 
a

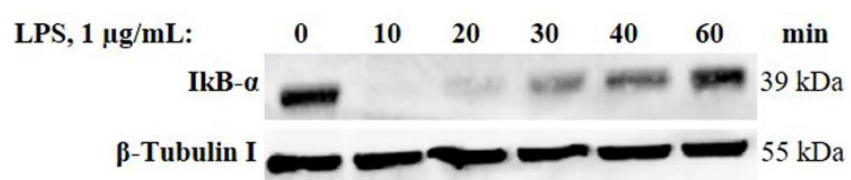

b

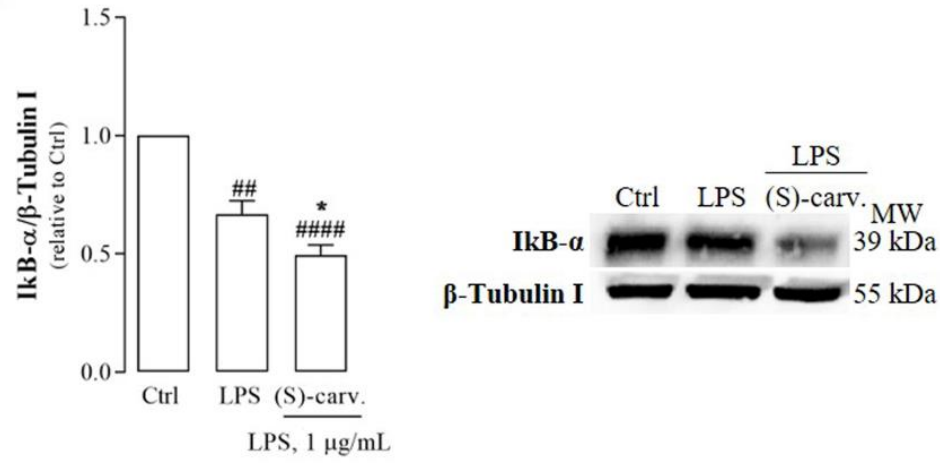

Figure 5. Effect of (S)-(+)-carvone on LPS-induced IkB- $\alpha$ resynthesis in Raw 264.7 macrophages. (a) Time course of LPS-induced IkB- $\alpha$ degradation and resynthesis. The cells were treated with $1 \mu \mathrm{g} / \mathrm{mL}$ LPS for the time periods indicated. (b) The cells were treated with the vehicle (0.1\% DMSO) or $665 \mu \mathrm{M}(\mathrm{S})-(+)$-carvone [(S)-carv.] for $1 \mathrm{~h}$, followed by stimulation with $1 \mu \mathrm{g} / \mathrm{mL}$ LPS for $1 \mathrm{~h}$. Control cells (Ctrl) were treated with the vehicle alone. Each column represents the mean \pm SEM of seven independent experiments. Representative images are shown. ${ }^{*} p<0.05$ relative to LPS-treated cells. ${ }^{\# \#} p<0.01$ and ${ }^{\# \# \#} p<0.0001$ relative to the Ctrl. MW: molecular weight marker.
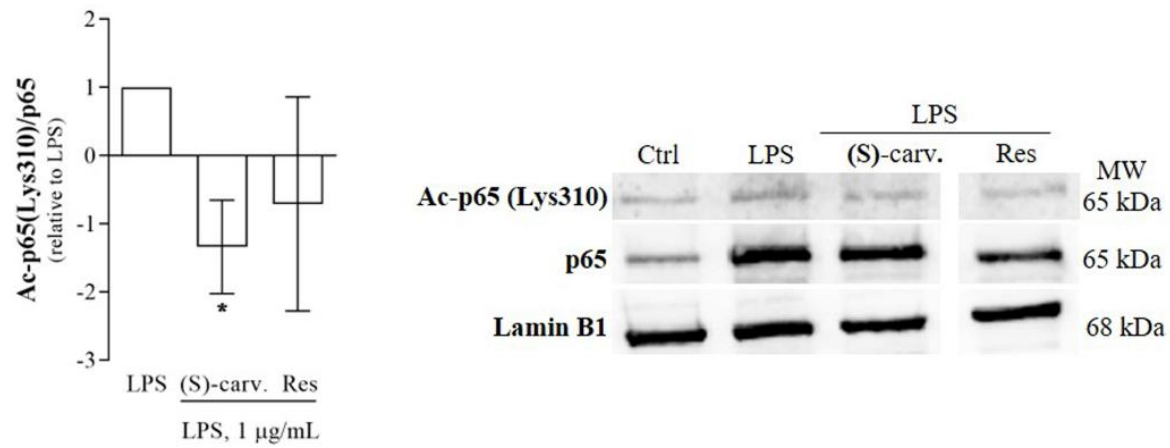

Figure 6. Effect of (S)-(+)-carvone on Lys310-acetylated NF-кB/p65 levels. Raw 264.7 macrophages were pre-treated with the vehicle $(0.1 \% \mathrm{DMSO}), 665 \mu \mathrm{M}(\mathrm{S})-(+)$-carvone [(S)-carv.] or $5.5 \mu \mathrm{M}$ Resveratrol (Res) for $1 \mathrm{~h}$, before treatment with $1 \mu \mathrm{g} / \mathrm{mL}$ LPS, for $1 \mathrm{~h}$. Each column represents the mean \pm SEM of the ratio between Ac-p65 (Lys310) and total NF-kB/p65 levels, after subtraction of the volume of the corresponding bands obtained in control cells. The results were then normalized to the ratio obtained in LPS-treated cells. The images shown are representative of four independent experiments. ${ }^{*} p<0.05$ relative to LPS-treated cells. MW: molecular weight marker.

\section{6. (S)-(+)-Carvone Activates SIRT1 without Affecting Its Protein Levels}

Deacetylation of Lys310 on NF-kB/p65 is specifically mediated by Sirtuin-1 (SIRT1), a NAD ${ }^{+}$-dependent class III histone/protein deacetylase, leading to inhibition of NF- $\mathrm{KB}$ transcriptional activity [12]. Increased deacetylation of SIRT1 target proteins can occur in response to stimuli that increase the protein levels of the enzyme, with or without affecting its activity [21,22]. Thus, to further elucidate the mechanism underlying the ability of (S)-(+)-carvone to deacetylate NF-kB/p65, we evaluated the protein levels of SIRT1 upon treatment of macrophage cultures with LPS for $1 \mathrm{~h}$, in the presence and absence of the test compound. Figure 7a shows that SIRT1 protein levels remained constant upon LPS treatment either in the presence or absence of (S)-(+)-carvone. 
a
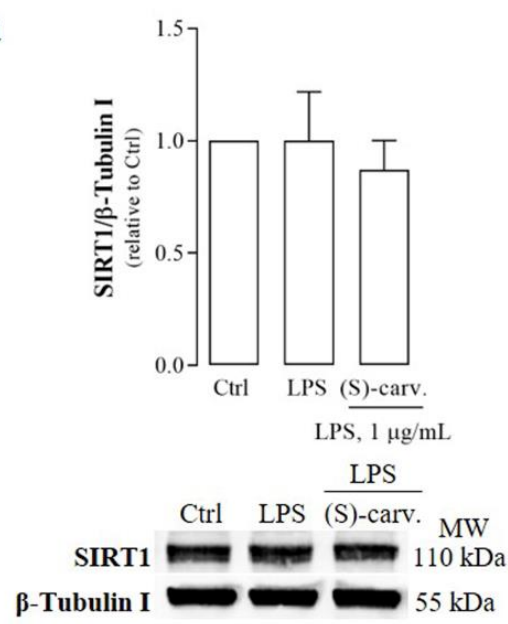

b

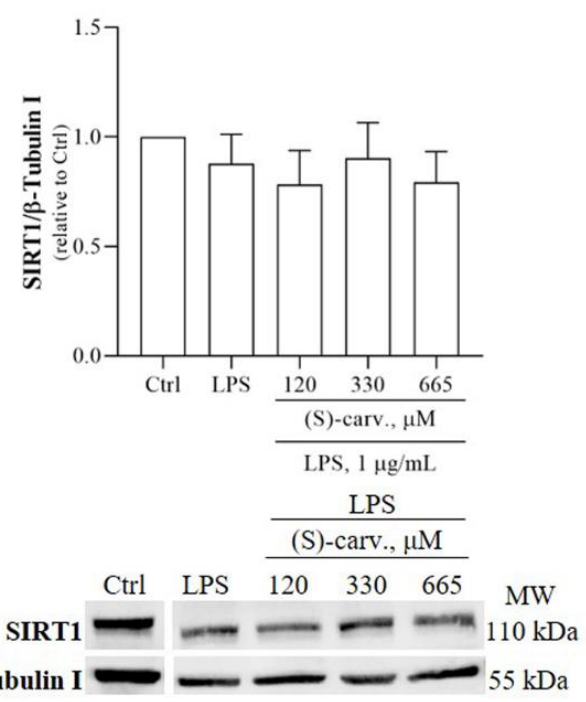

c

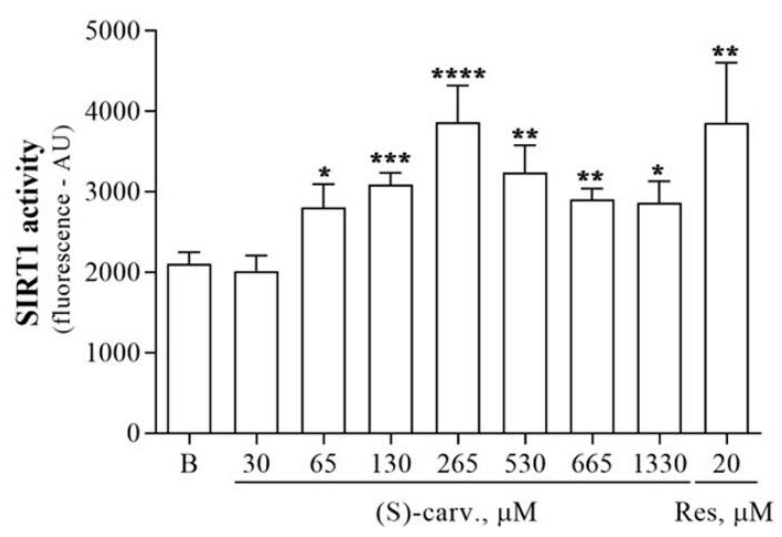

Figure 7. Effect of (S)-(+)-carvone on SIRT1 protein levels and activity. (a) and (b) Raw 264.7 cells

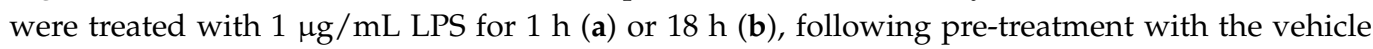
(0.1\% DMSO), $665 \mu \mathrm{M}$ (a) or the indicated concentrations (b) of (S)-(+)-carvone [(S)-carv.] for $1 \mathrm{~h}$. Control cells (Ctrl) were treated with the vehicle (0.1\% DMSO) alone. Each column represents the mean \pm SEM of three (a) and six (b) independent experiments. Representative images are shown. MW: molecular weight marker. (c) The activity of human recombinant SIRT1 was measured as the amount of fluorescent product released by deacetylation of a specific fluorogenic peptide substrate, in the presence or absence (basal activity, B) of the indicated concentrations of (S)-(+)-carvone [(S)-carv.] or Resveratrol (Res), used as a pharmacological control of SIRT1 activation. Fluorescence intensity is directly proportional to SIRT1 activity. Results are presented as mean fluorescence intensity in arbitrary units \pm SEM. Each concentration of (S)-(+)-carvone [(S)-carv.] and Res was tested at least 6 times. ${ }^{*} p<0.05,{ }^{* *} p<0.01,{ }^{* * *} p<0.001$ and ${ }^{* * *} p<0.0001$ relative to the basal SIRT1 activity. B: basal SIRT1 activity.

To further determine whether (S)-(+)-carvone can modulate SIRT1 protein levels independently of its effects on NF- $\mathrm{KB}$ activity, we tested a time point sufficiently distal to be independent of the effects on NF- $\mathrm{kB}$. Figure $7 \mathrm{~b}$ shows that even after treatment for $18 \mathrm{~h}$, SIRT1 protein levels remained identical in cells treated with LPS alone and in the presence of (S)-(+)-carvone.

Then, we investigated the ability of (S)-(+)-carvone to directly enhance the activity of SIRT1. For this, we used an in vitro fluorometric assay based on the ability of recombinant human SIRT1 to deacetylate a synthetic peptide derived from p53, a prototypical SIRT1 substrate [23]. Figure 7c shows that the basal enzyme activity increased in the presence 
of different concentrations of (S)-(+)-carvone, reaching a maximum increase of $84 \%$ at a concentration of $265 \mu \mathrm{M}$. As expected, Res, a known SIRT1 activator, was also effective in increasing basal SIRT1 activity.

Taken together, the results show that (S)-(+)-carvone promoted NF-kB/p65 deacetylation, likely by directly activating SIRT1, and this mechanism probably underlies the inhibitory effect of (S)-(+)-carvone on NF-kB-dependent gene transcription.

\section{Discussion}

Inhibition of MAPK and/or NF- $\mathrm{BB}$ signaling pathways are mechanisms relevant to dampen chronic low-grade inflammation that are targeted by many compounds of natural origin [24,25], from polyphenols, such as Res [26], to monoterpenes, such as myrcene, limonene [27] and $\alpha$-pinene [28]. Thus, to elucidate the molecular mechanism of the antiinflammatory effects of (S)-(+)-carvone that we observed in murine macrophages and human chondrocytes [7], we started by evaluating its ability to inhibit those signaling pathways. Interestingly, the results demonstrate that only JNK1 is significantly inhibited by (S)-(+)-carvone (Figure $2 b$ ), while it does not prevent LPS-induced activation of any of the other MAPK family members to a significant extent (Figure 2a,d). Nonetheless, inhibition of JNK1 may contribute to the anti-inflammatory effects that we and others previously observed with (S)-(+)-carvone. In fact, activation of this MAPK enhances the activity of pro-inflammatory transcription factors, namely, NF-кB [29] and Activator Protein-1 [30,31], which are crucial to the expression of inflammatory mediators, such as NOS2 [32,33] and matrix metalloproteases [34,35], in response to various stimuli, in different cells.

On the other hand, (S)-(+)-carvone did not prevent any of the steps involved in the canonical NF- $\kappa$ B activation pathway, that is, I $\kappa \mathrm{B}-\alpha$ phosphorylation and degradation and NFkB/p65 nuclear translocation and phosphorylation on Ser536 (Figures 3 and 4). Nonetheless, we further confirmed that this compound is effective in inhibiting the expression of IкB- $\alpha$, another NF- $\mathrm{BB}$ target gene (Figure 5).

Since several post-translational modifications of NF- $\mathrm{B} / \mathrm{p} 65$ play a critical role in modulating its DNA-binding affinity and transcriptional activity [18], we hypothesized that (S)-(+)-carvone may exert its anti-inflammatory effects by modulating such modifications. Among those post-translational modifications, acetylation of Lys310 by the co-activator and histone/protein acetyltransferase, $\mathrm{CBP} / \mathrm{p} 300$, is required for the full transcriptional activity of NF- $\mathrm{B}$, without interfering with DNA binding [18]. Deacetylation of that Lys residue prevents and contributes to cease NF- $\mathrm{KB}$ transcriptional activity because it allows for the subsequent ubiquitination and degradation of promoter-associated NF- $\mathrm{B} / \mathrm{p} 65$ [18]. As shown in Figure 6, (S)-(+)-carvone significantly decreased the levels of NF- $\mathrm{kB} / \mathrm{p} 65$ acetylated on Lys310 induced by LPS in mouse macrophages, suggesting that this can be the mechanism underlying the inhibition of NF- $\mathrm{BB}$-dependent gene expression.

Decreased levels of acetylated NF-KB/p65 can occur due to the inhibition of acetyltransferase (HAT) enzymes or the activation of histone/protein deacetylases (HDAC). Among HDACs, SIRT1 has a major role in modulating NF- $\mathrm{kB}$ transcriptional activity by directly interacting with and deacetylating NF-кB/p65 on Lys310 [12]. Thus, we hypothesized that (S)-(+)-carvone could target SIRT1. The results presented in Figure 7 confirmed this hypothesis, showing that (S)-(+)-carvone significantly increases the basal activity of human recombinant SIRT1 without affecting its protein levels.

To our knowledge, this is the first study identifying a monoterpene compound as a direct activator of SIRT1. Although studies using (S)-(+)-carvone are scarce, previous studies using the racemic mixture containing both carvone enantiomers, (S)-(+)- and (R)-(-)-carvone, reported some pharmacological activities, including antioxidant [9], anti-inflammatory [7,8], anti-carcinogenic [36], anti-hyperglycemic and anti-hyperlipidemic [10,11] properties. Interestingly, SIRT1 activation has been shown to have a role in all these processes [37,38], suggesting that, at least in part, this can be the mechanism underlying the pharmacological activities previously reported for carvone. 
Remarkably, NF-KB and SIRT1 are involved in an antagonistic crosstalk whereby SIRT1 inhibits NF- $\mathrm{KB}$ activity by deacetylating NF- $\mathrm{kB} / \mathrm{p} 65$ while this transcription factor inhibits SIRT1 expression [39]. Decreased SIRT1 expression and increased NF- $\mathrm{KB}$ activity are found in many metabolic and age-related diseases, so that SIRT1 activation and NF- $\mathrm{kB}$ inhibition are envisaged as promising therapeutic strategies for those diseases, as well as to delay the consequences of aging $[38,40,41]$. Interestingly, recent studies showed that inhibitors of the sodium-glucose cotransporter-2, used in the therapy of type 2 diabetes, have cardioprotective effects in heart failure related to the systemic activation of SIRT1 and probably to the induction of SIRT1 expression in the heart [42]. Therefore, the ability of (S)-(+)-carvone to directly increase the activity of SIRT1 has huge therapeutic potential. Additional studies addressed at pharmacokinetic and further pharmacodynamic elucidation, namely, in terms of selectivity, efficacy and safety, in cell and animal models of disease are required to fully ascertain the therapeutic potential of (S)-(+)-carvone. On the other hand, the identification of a non-polyphenolic compound, (S)-(+)-carvone, as a SIRT1 activator opens up the possibility that other monoterpene compounds, in particular those that share structural features, like the $p$-menthane backbone, may also present the same property, presenting new perspectives and opportunities for the pharmacological modulation of SIRT1.

\section{Conclusions}

In summary, the results presented show that (S)-(+)-carvone, a $p$-menthane-derived monoterpene, is able to directly activate SIRT1, enhancing NF- $\mathrm{kB} / \mathrm{p} 65$ deacetylation and decreasing its transcriptional activity and the consequent inflammatory response. (S)-(+)carvone is the first non-polyphenolic compound found to directly activate SIRT1, opening up new perspectives and opportunities for the development of novel drugs to target numerous diseases in which SIRT1 plays a protective role.

Author Contributions: Conceptualization: A.F.M., C.S.; Data curation: C.S.; Formal analysis: C.S.; Funding acquisition: A.F.M.; Investigation: C.S., B.M.N.; Project administration: A.F.M.; Resources: A.F.M.; Supervision: A.F.M.; Validation: A.F.M., A.J.L.; Visualization: A.F.M., C.S.; Writing—original draft: C.S.; Writing—review and editing: A.F.M., C.S., A.J.L. All authors have read and agreed to the published version of the manuscript.

Funding: This work was funded by the European Regional Development Fund (ERDF), through the Centro 2020 Regional Operational Program under projects POCI-01-0145-FEDER-CARTILFACTORY and CENTRO-01-0145-FEDER-HealthyAging2020 and through the COMPETE 2020-Operational Program for Competitiveness and Internationalization and Portuguese national funds via FCT-Fundação para a Ciência e a Tecnologia, under projects POCI-01-0145-FEDER-028424, CENTRO-01-0145FEDER-007440, UIDB/04539/2020, UIDP/04539/2020 and the PhD fellowship, SFRH/79600/2011, to C. Sousa.

Institutional Review Board Statement: Not applicable.

Informed Consent Statement: Not applicable.

Data Availability Statement: All data are available from the corresponding author upon request.

Conflicts of Interest: C.S., A.J.L. and A.F.M. are co-inventors of a PCT international application concerning (S)-(+)-carvone as a Sirtuin-1 activator, recently filed by the University of Coimbra and the Center for Neuroscience and Cell Biology to the World Intellectual Property Organization. B.M.N. declares no competing interests.

\section{References}

1. Medzhitov, R. Inflammation 2010: New adventures of an old flame. Cell 2010, 140, 771-776. [CrossRef]

2. Malaquin, N.; Martinez, A.; Rodier, F. Keeping the senescence secretome under control: Molecular reins on the senescenceassociated secretory phenotype. Exp. Gerontol. 2016, 82, 39-49. [CrossRef]

3. Maniaci, A.; Iannella, G.; Cocuzza, S.; Vicini, C.; Magliulo, G.; Ferlito, S.; Cammaroto, G.; Meccariello, G.; De Vito, A.; Nicolai, A.; et al Oxidative Stress and Inflammation Biomarker Expression in Obstructive Sleep Apnea Patients. J. Clin. Med. 2021, 10, 277. [CrossRef] 
4. $\quad$ Chen, L.; Deng, H.; Cui, H.; Fang, J.; Zuo, Z.; Deng, J.; Li, Y.; Wang, X.; Zhao, L. Inflammatory responses and inflammationassociated diseases in organs. Oncotarget 2018, 9, 7204-7218. [CrossRef] [PubMed]

5. Gupta, S.C.; Sundaram, C.; Reuter, S.; Aggarwal, B.B. Inhibiting NF-kappaB activation by small molecules as a therapeutic strategy. Biochim. Biophys. Acta 2010, 1799, 775-787. [CrossRef] [PubMed]

6. Kaminska, B. MAPK signalling pathways as molecular targets for anti-inflammatory therapy-from molecular mechanisms to therapeutic benefits. Biochim. Biophys. Acta 2005, 1754, 253-262. [CrossRef]

7. Sousa, C.; Leitão, A.J.; Neves, B.M.; Judas, F.; Cavaleiro, C.; Mendes, A.F. Standardised comparison of limonene-derived monoterpenes identifies structural determinants of anti-inflammatory activity. Sci. Rep. 2020, 10, 7199. [CrossRef] [PubMed]

8. Sepúlveda-Arias, J.C.; Veloza, L.A.; Escobar, L.M.; Orozco, L.M.; Lopera, I.A. Anti-inflammatory effects of the main constituents and epoxides derived from essential oils obtained from Tagetes lucida, Cymbopogon citratus, Lipia alba and Eucalyptus citriodora. J. Essent. Oil Res. 2013, 25, 186-193. [CrossRef]

9. Sabir, S.M.; Singh, D.; Rocha, J.B.T. In Vitro Antioxidant Activity of S-Carvone Isolated from Zanthoxylum alatum. Pharm. Chem. J. 2015, 49, 187-191. [CrossRef]

10. Muruganathan, U.; Srinivasan, S. Beneficial effect of carvone, a dietary monoterpene ameliorates hyperglycemia by regulating the key enzymes activities of carbohydrate metabolism in streptozotocin-induced diabetic rats. Biomed. Pharmacother. 2016, 84, $1558-1567$. [CrossRef]

11. Alsanea, S.; Liu, D. BITC and S-Carvone Restrain High-Fat Diet-Induced Obesity and Ameliorate Hepatic Steatosis and Insulin Resistance. Pharm. Res. 2017, 34, 2241-2249. [CrossRef]

12. Yeung, F.; Hoberg, J.E.; Ramsey, C.S.; Keller, M.D.; Jones, D.R.; Frye, R.A.; Mayo, M.W. Modulation of NF-kappaB-dependent transcription and cell survival by the SIRT1 deacetylase. EMBO J. 2004, 23, 2369-2380. [CrossRef] [PubMed]

13. Sousa, C.; Ribeiro, M.; Rufino, A.T.; Leitao, A.J.; Mendes, A.F. Assessment of cell line competence for studies of pharmacological GPR30 modulation. J. Recept. Signal Transduct. Res. 2017, 37, 181-188. [CrossRef] [PubMed]

14. Roy, A.; Srivastava, M.; Saqib, U.; Liu, D.; Faisal, S.M.; Sugathan, S.; Bishnoi, S.; Baig, M.S. Potential therapeutic targets for inflammation in toll-like receptor 4 (TLR4)-mediated signaling pathways. Int. Immunopharmacol. 2016, 40, 79-89. [CrossRef] [PubMed]

15. Sakurai, H.; Chiba, H.; Miyoshi, H.; Sugita, T.; Toriumi, W. IkappaB kinases phosphorylate NF-kappaB p65 subunit on serine 536 in the transactivation domain. J. Biol. Chem. 1999, 274, 30353-30356. [CrossRef]

16. Yang, F.; Tang, E.; Guan, K.; Wang, C.Y. IKK beta plays an essential role in the phosphorylation of RelA/p65 on serine 536 induced by lipopolysaccharide. J. Immunol. 2003, 170, 5630-5635. [CrossRef]

17. Cheng, J.D.; Ryseck, R.P.; Attar, R.M.; Dambach, D.; Bravo, R. Functional redundancy of the nuclear factor kappa B inhibitors I kappa B alpha and I kappa B beta. J. Exp. Med. 1998, 188, 1055-1062. [CrossRef]

18. Huang, B.; Yang, X.D.; Lamb, A.; Chen, L.F. Posttranslational modifications of NF-kappaB: Another layer of regulation for NF-kappaB signaling pathway. Cell. Signal. 2010, 22, 1282-1290. [CrossRef]

19. Holmes-McNary, M.; Baldwin, A.S., Jr. Chemopreventive properties of trans-resveratrol are associated with inhibition of activation of the IkappaB kinase. Cancer Res. 2000, 60, 3477-3483.

20. Manna, S.K.; Mukhopadhyay, A.; Aggarwal, B.B. Resveratrol suppresses TNF-induced activation of nuclear transcription factors NF-kappa B, activator protein-1, and apoptosis: Potential role of reactive oxygen intermediates and lipid peroxidation. J. Immunol. 2000, 164, 6509-6519. [CrossRef]

21. Kim, S.C.; Kim, Y.H.; Son, S.W.; Moon, E.Y.; Pyo, S.; Um, S.H. Fisetin induces Sirt1 expression while inhibiting early adipogenesis in 3T3-L1 cells. Biochem. Biophys. Res. Commun. 2015, 467, 638-644. [CrossRef]

22. Miao, Y.; Zhao, S.; Gao, Y.; Wang, R.; Wu, Q.; Wu, H.; Luo, T. Curcumin pretreatment attenuates inflammation and mitochondrial dysfunction in experimental stroke: The possible role of Sirt1 signaling. Brain Res. Bull. 2016, 121, 9-15. [CrossRef]

23. Dai, H.; Sinclair, D.A.; Ellis, J.L.; Steegborn, C. Sirtuin activators and inhibitors: Promises, achievements, and challenges. Pharmacol. Ther. 2018. [CrossRef]

24. Lin, G.D.; Li, R.W. Chapter 10-Natural Products Targeting Inflammation Processes and Multiple Mediators. In Natural Products and Drug Discovery; Mandal, S.C., Mandal, V., Konishi, T., Eds.; Elsevier: Amsterdam, The Netherlands, 2018; pp. $277-308$.

25. Azab, A.; Nassar, A.; Azab, A.N. Anti-Inflammatory Activity of Natural Products. Molecules 2016, 21, 1321. [CrossRef] [PubMed]

26. de Sá Coutinho, D.; Pacheco, M.T.; Frozza, R.L.; Bernardi, A. Anti-Inflammatory Effects of Resveratrol: Mechanistic Insights. Int. J. Mol. Sci. 2018, 19, 1812. [CrossRef] [PubMed]

27. Rufino, A.T.; Ribeiro, M.; Sousa, C.; Judas, F.; Salgueiro, L.; Cavaleiro, C.; Mendes, A.F. Evaluation of the anti-inflammatory, anti-catabolic and pro-anabolic effects of E-caryophyllene, myrcene and limonene in a cell model of osteoarthritis. Eur. J. Pharmacol. 2015, 750, 141-150. [CrossRef]

28. Rufino, A.T.; Ribeiro, M.; Judas, F.; Salgueiro, L.; Lopes, M.C.; Cavaleiro, C.; Mendes, A.F. Anti-inflammatory and chondroprotective activity of (+)-alpha-pinene: Structural and enantiomeric selectivity. J. Nat. Prod. 2014, 77, 264-269. [CrossRef] [PubMed]

29. Wolter, S.; Doerrie, A.; Weber, A.; Schneider, H.; Hoffmann, E.; von der Ohe, J.; Bakiri, L.; Wagner, E.F.; Resch, K.; Kracht, M. c-Jun controls histone modifications, NF-kappaB recruitment, and RNA polymerase II function to activate the ccl2 gene. Mol. Cell. Biol. 2008, 28, 4407-4423. [CrossRef] [PubMed] 
30. Hambleton, J.; Weinstein, S.L.; Lem, L.; DeFranco, A.L. Activation of c-Jun N-terminal kinase in bacterial lipopolysaccharidestimulated macrophages. Proc. Natl. Acad. Sci. USA 1996, 93, 2774-2778. [CrossRef] [PubMed]

31. Meng, Q.; Xia, Y. c-Jun, at the crossroad of the signaling network. Protein Cell 2011, 2, 889-898. [CrossRef]

32. Spitsin, S.V.; Koprowski, H.; Michaels, F.H. Characterization and functional analysis of the human inducible nitric oxide synthase gene promoter. Mol. Med. 1996, 2, 226-235. [CrossRef]

33. Martin, M.U.; Wesche, H. Summary and comparison of the signaling mechanisms of the Toll/interleukin-1 receptor family. Biochim. Et Biophys. Acta 2002, 1592, 265-280. [CrossRef]

34. Catterall, J.B.; Carrère, S.; Koshy, P.J.; Degnan, B.A.; Shingleton, W.D.; Brinckerhoff, C.E.; Rutter, J.; Cawston, T.E.; Rowan, A.D. Synergistic induction of matrix metalloproteinase 1 by interleukin-1alpha and oncostatin $\mathrm{M}$ in human chondrocytes involves signal transducer and activator of transcription and activator protein 1 transcription factors via a novel mechanism. Arthritis Rheum. 2001, 44, 2296-2310. [CrossRef]

35. Mengshol, J.A.; Vincenti, M.P.; Brinckerhoff, C.E. IL-1 induces collagenase-3 (MMP-13) promoter activity in stably transfected chondrocytic cells: Requirement for Runx-2 and activation by p38 MAPK and JNK pathways. Nucleic Acids Res. 2001, 29, 4361-4372. [CrossRef]

36. Wattenberg, L.W.; Sparnins, V.L.; Barany, G. Inhibition of N-nitrosodiethylamine carcinogenesis in mice by naturally occurring organosulfur compounds and monoterpenes. Cancer Res. 1989, 49, 2689-2692.

37. Haigis, M.C.; Sinclair, D.A. Mammalian sirtuins: Biological insights and disease relevance. Annu. Rev. Pathol. 2010, 5, 253-295. [CrossRef]

38. Gomes, P.; Leal, H.; Mendes, A.F.; Reis, F.; Cavadas, C. Dichotomous Sirtuins: Implications for Drug Discovery in Neurodegenerative and Cardiometabolic Diseases. Trends Pharmacol. Sci. 2019, 40, 1021-1039. [CrossRef] [PubMed]

39. Kauppinen, A.; Suuronen, T.; Ojala, J.; Kaarniranta, K.; Salminen, A. Antagonistic crosstalk between NF-kappaB and SIRT1 in the regulation of inflammation and metabolic disorders. Cell. Signal. 2013, 25, 1939-1948. [CrossRef] [PubMed]

40. Mahmoudi, S.; Xu, L.; Brunet, A. Turning back time with emerging rejuvenation strategies. Nat. Cell Biol. 2019, 21, 32-43. [CrossRef] [PubMed]

41. Gaspar, L.S.; Álvaro, A.R.; Carmo-Silva, S.; Mendes, A.F.; Relógio, A.; Cavadas, C. The importance of determining circadian parameters in pharmacological studies. Br. J. Pharmacol. 2019, 176, 2827-2847. [CrossRef] [PubMed]

42. Packer, M. Cardioprotective Effects of Sirtuin-1 and Its Downstream Effectors: Potential Role in Mediating the Heart Failure Benefits of SGLT2 (Sodium-Glucose Cotransporter 2) Inhibitors. Circulation. Heart Fail. 2020, 13, e007197. [CrossRef] [PubMed] 